\title{
Dramaturgia do esgotamento: estudo genético d'A Última Palavra É a Penúltima 2.o, do Teatro da Vertigem
}

MARIA CLARA FERRER

This essay focuses on the genetics of $A$ Última Palavra É a Penúltima 2.0 [The Last Word Is the One Before the Last 2.0], a performance created by Teatro da Vertigem, in October 2014, for the São Paulo Art Biennal, based on Gilles Deleuze's essay, The Depleted, inspired by Samuel Beckett's work. The performance, directed by Eliane Monteiro and Antônio Araújo, stands apart from their previous collective creations, as it is the first time that the group hasn't used a dramaturge and rejects the usage of a text. This is why we are trying to understand and demonstrate how the concept of depletion, suggested by Deleuze, infiltrates itself as an active principle into the dramaturgical construction of the creation, breaking apart from the structural function of the text and promoting a choreographic characterised performance. The genetic approach will be developed on the basis of interviews with the members of the group, as well as on the analysis of the director's note book.

DEPLETION / SAMUEL BECKETT / VERTIGEM / DRAMATURGY WITHOUT TEXT / SITE SPECIFIC

A importância conquistada pelo Teatro da Vertigem no panorama teatral brasileiro reflete, ao longo dos vinte e cinco anos de sua história, a ousadia e o engajamento político de suas propostas artísticas. Desde seu primeiro espetáculo, O Paraíso Perdido (1992) que estreia na Igreja de Santa Ifigênia em São Paulo, a companhia leva o teatro para fora dos espaços convencionais e põe em prática um trabalho in site specific (in situ). Optando por lugares fortemente simbólicos da metrópole, tais como o rio Tietê, o antigo presídio do Hipódromo ou ainda o bairro do Bom Retiro, as criações do Vertigem se caracterizam por dramaturgias que dialogam intimamente com a cidade. Neste sentido, a estética elaborada pelo grupo pode se inscrever no que Paul Ardenne define como arte contextual («Art contextuel»), pois, nos diferentes espetáculos da companhia, são as condições e o contexto de criação da obra que produzem o seu sentido, fazendo que o espaço se torne o protagonista da ação. 
Abordaremos aqui o espetáculo A Última Palavra É a Penúltima 2.o. Trata-se de uma recriação (pois o espetáculo já havia conhecido uma primeira versão em 2008), codirigida por Eliane Monteiro e Antônio Araújo e realizada em outubro de 2014 para a Bienal de Arte de São Paulo. Inspirado pelo ensaio O Esgotado, de Gilles Deleuze - obra na qual o filósofo, analisando a obra de Samuel Beckett, evidencia as figuras e os mecanismos do esgotamento nos textos do autor -, A Última Palavra É a Penúltima 2.o assume um caráter inédito na trajetória da companhia. Até então, para cada uma de suas criações, o coletivo tinha o hábito de convidar um dramaturgo que acompanhava os ensaios e ficava encarregado da escrita do texto. Ora, no processo de criação d'A Última Palavra É a Penúltima 2.o, abre-se mão da presença desta figura do autor convidado e cria-se, pela primeira vez, um espetáculo sem texto, ou seja, uma dramaturgia na qual a palavra, além de muito escassa e muitas vezes incompreensível, não exerce nenhum papel estruturante. Tal escolha marca, de certo modo, uma ruptura com o funcionamento de criação dramatúrgica próprio da genética de seus outros espetáculos. Portanto, parece importante questionar não somente as razões da ausência de texto em $A$ Última Palavra É a Penúltima 2.o, mas também os procedimentos e ferramentas de trabalho que forjaram a dramaturgia desta obra.

Para tanto, vamos nos deixar nortear pela hipótese de que o conceito de esgotamento, tal como definido no ensaio de Deleuze, se infiltra na dramaturgia e na estética do espetáculo como um princípio ativo - e não como uma simples metáfora ou referência aparente no título (que é uma citação do texto de Deleuze) -, produzindo uma dramaturgia sem texto. $\mathrm{O}$ estudo genético proposto se baseia em três tipos de registros sobre o processo de criação do espetáculo: duas entrevistas realizadas com a diretora Eliane Monteiro e com o ator Nicolas Gonzáles, o documentário sobre o processo de criação realizado por Evaldo Mocarzel e o caderno de anotações utilizado pela encenadora durante o processo.

\section{A METODOLOGIA DO PROCESSO COLABORATIVO E A IMPORTÂNCIA DO CADERNO DE ENSAIO COMO SUBTEXTO DA CRIAÇÃO}

Não podemos nos debruçar sobre a especificidade dramatúrgica d'A Última Palavra É a Penúltima 2.o sem antes destacarmos o modo de produção dramatúrgico que vem sendo elaborado e empregado pela companhia desde sua primeira criação. Neste sentido, é válido lembrar, 
levando em conta a forte identidade de sua linha de pesquisa, o quão a genética in site specific dos espetáculos do Teatro da Vertigem está ligada a uma metodologia de trabalho criativo própria, batizada por Antônio Araújo de processo colaborativo. Trata-se de uma organização na qual «todos os integrantes [...] têm igual espaço propositivo, produzindo uma obra cuja autoria é compartilhada por todos» (Araújo, 2011: 131), explica o diretor. Assim sendo, o coletivo não adere ao caráter consecutivo da criação teatral, onde a escrita do texto precede o tempo de sua encenação. Na maioria das vezes, o ponto de partida dos espectáculos do coletivo é um questionamento de cunho sociopolítico ligado a problemáticas da cidade grande, e não uma peça de teatro previamente escrita. A cada novo espetáculo, o grupo convida um dramaturgo externo que participa ativamente do processo de criação escrevendo o texto junto aos atores. A dramaturgia nasce portanto de um longo trâmite entre diretores, atores e dramaturgo. O texto, composto por esse último, costuma atravessar numerosas versões ao longo do processo até chegar a sua forma final.

A rotina do processo colaborativo, tal como este foi desenvolvido pelo Vertigem, é marcado pela prática preponderante do que o grupo chama de workshop. O workshop é uma proposta cênica (com ou sem palavras) que cada ator deve elaborar em resposta a uma indicação/provocação dos diretores. Estruturando o cotidiano dos ensaios do Vertigem, o workshop, espécie de «dever de casa» criativo do ator, é o exercício fundamental, o núcleo duro do processo colaborativo. Ele tem por objetivo estimular o potencial criativo do grupo, levantando um material cênico e desenvolvendo uma linguagem coletiva que servirão de cartilha para a construção dramatúrgica do espetáculo. A acumulação inflacionária de workshops inaugura um imenso espaço de improvisação dramatúrgica alimentado por um intenso tráfico de propostas cênicas. $\mathrm{O}$ excesso de proposições põe muitas vezes o dramaturgo em uma posição desconfortável, tendo de conciliar e lidar na criação do texto com as diferentes subjetividades que se expressam ao longo do processo.

Já aos diretores, Antônio Araújo e Eliane Monteiro, cabe organizar, fazer a triagem cotidiana, comentar e destrinçar as inúmeras propostas vindas dos workshops. Isso demanda um considerável tempo de preparação dos ensaios e de discussões com os atores, momentos importantes nos quais os diretores analisam e comentam os workshops. Essa rígida estruturação cotidiana dos ensaios ganha corpo no caderno de criação dos diretores, peça-chave para se estudar a genética dos espetáculos do Teatro da Vertigem. A dramaturgia in progress se reflete nos enunciados 
dos workshops, anotações e comentários dos mesmos, nas listas, tabelas e nas palavras-chave que mapeiam as páginas de cada criação e estruturam pouco a pouco a imaginação coletiva do grupo através de um léxico que vai se afirmando nas notas dos encenadores. Nasce assim não um texto que será dito pelos atores, mas um subtexto que condensa as ideias, imagens e dinâmicas essenciais de cada espetáculo.

Diferentemente dos cadernos de criação de encenadores como Robert Wilson ou Jan Fabre, que desenham suas visões cênicas projetando ali aquilo que imaginam criar no palco, os cadernos de Antônio Araújo e Eliane Monteiro revelam o exercício cotidiano da alteridade, característica do processo colaborativo, retratando o diálogo do dia a dia dos ensaios e as construções e lógicas cênicas que deles emergem. É o que teremos a ocasião de explorar através do estudo genético d'A Última Palavra É a Penúltima é 2.o.

O ponto de partida do processo criativo d'A Última Palavra É a Penúltima 2.o foi a leitura do ensaio de Gilles Deleuze O Esgotado. Esta desperta no coletivo o desejo de criar uma intervenção urbana partindo da seguinte questão: o que me esgota na cidade grande? Como o esgotamento se manifesta na vida da megalópole tentacular que é São Paulo? Na entrevista concedida, Eliane Monteiro relata as impressões do grupo relativamente a estas indagações. O primeiro ponto evidenciado, explica a encenadora, foi o excesso de câmeras de segurança espalhadas pela metrópole. «Saber-se constantemente filmado e controlado é uma forma de esgotamento cotidiano na vida do paulistano» (Monteiro, 2015). Outra forma de esgotamento debatida pelo grupo foi a falta de horizonte criada pela forte aglomeração arquitetônica da cidade, impedindo o olhar do transeunte de se projetar em direção ao infinito. Essas duas intuições guiaram a escolha do espaço para a performance. «Era preciso, explica ela, um lugar fechado que encurtasse a visão do espectador, para que a sensação de enclausuramento se tornasse palpável, mas também tinha que ser um lugar de passagem onde houvesse um fluxo urbano contínuo» (ibidem).

O grupo opta assim por um acesso subterrâneo da rua Xavier de Toledo no centro da cidade, que liga o caótico Viaduto do Chá e a movimentada praça Ramos de Azevedo, onde se encontra o Teatro Municipal. 
Além de sua localização estratégica, a passagem Xavier de Toledo possuía uma outra característica que atraiu o coletivo: suas paredes são beiradas por vitrinas vazias que abrigavam no passado lojas comerciais. Ali foram instalados de maneira bifrontal os espectadores, cinquenta ao todo, sentados em bancos postos atrás dos vidros das vitrinas. Criando um «lugar da onde se vê», o dispositivo transforma o túnel em um espaço cênico, frenética passarela urbana onde desfilam em fluxo contínuo as silhuetas paulistanas. Além disso, para traduzir o esgotamento gerado pela sociedade de controlo, foram instaladas câmeras dentro e fora da passagem, projetando simultaneamente em telões o que ocorria dentro do túnel e por cima dele.

Na medida em que o grupo não pretendia interromper a circulação da passagem, mas jogar com ela, o acesso não foi interditado. Havia, portanto, duas categorias de espectadores: os que tinham ingresso e ficavam sentados dentro das vitrinas e aqueles que por ali passavam e se confundiam com os atores. É importante notar que a própria instalação, criada para trazer à tona as impressões de esgotamento na cidade de São Paulo, acaba por determinar a ausência de texto. Segundo Eliane Monteiro, «a estruturação textual da ação acarretaria na redução ou na estagnação do fluxo dentro da passagem. O importante era que as imagens falassem por si só e a presença de texto poderia se tornar um comentário daquilo que se via» (ibidem).

Explorando esta ideia, cabe aqui ressaltar que a palavra, de modo geral, exerce, dentro da lógica humana de percepção do espaço, um efeito de focalização da atenção. Sobre este aspecto, os trabalhos de Michel Chion, pesquisador francês especializado nas relações entre o som e a imagem, podem nos ajudar a compreender o quão a atenção sonora é guiada pela escuta da voz, e mais especificamente da palavra. $\mathrm{O}$ autor utiliza o termo logocentrismo para designar os mecanismos que nos levam a privilegiar áudio e visualmente a palavra em relação aos outros sons que povoam nosso universo sonoro. No teatro, o fenômeno descrito por Chion é mais do que claro: quando um ator fala, diz um texto, cria em torno de si uma zona de concentração da atenção dos espectadores. Em outros termos, a palavra tem a faculdade de criar e modelar o tempo cênico, ela instala a ação, domando a atenção audiovisual dos espectadores. Era justamente esta tendência que os diretores d'A Última Palavra É a Penúltima 2.o queriam evitar: «queríamos manter a pulsação da cidade, sem interromper seu fluxo» (ibidem), relata Eliane Monteiro. Neste sentido, a ausência de texto também garante a participação dos 
transeuntes, que acabam por performar (voluntariamente ou não) dentro do dispositivo criado para a intervenção. «Caso se desenvolvesse ali um texto e uma história, os passantes ficariam intimidados e provavelmente não ousariam passar pelo túnel» (ibidem), explica a encenadora.

Uma vez que entendemos as razões que levaram o coletivo a renunciar ao papel estruturante do texto em A Última Palavra É a Penúltima 2.o, podemos nos perguntar como foi fabricada a dramaturgia do espetáculo. Para isso, vamos recorrer essencialmente à análise genética do caderno de ensaio de Eliane Monteiro, buscando destrinçar em suas páginas os eixos que nortearam a composição do roteiro. A leitura de suas notas permite distinguir duas partes do processo: a primeira marcada por cópia de citações d'O Esgotado e por enunciados e comentários dos workshops; e uma segunda onde se encontram predominantemente uma sequência de listas de ações. Dentro desta evolução, é importante entender como as citações escolhidas estimulam as sugestões dos workshops propostos pelos diretores, e como das propostas dos atores surge pouco a pouco o esqueleto do roteiro do espetáculo.

Em uma das primeiras páginas do caderno de notas, encontra-se uma citação d'O Esgotado posta em destaque por um enquadramento colorido. Trata-se das quatro modalidades de esgotamento do possível que Deleuze define a partir da obra de Beckett.

Há, pois, quatro maneiras de esgotar o possível:

- Formar séries exaustivas de coisas

- Estancar os fluxos da voz

- Extenuar as potencialidades do espaço

- Dissipar as potências da imagem (Deleuze, 2010: 70)

Cada uma dessas maneiras de esgotar o possível, como veremos em seguida, se infiltra de modo estruturante na constituição do roteiro do espetáculo. Primeiramente, o filósofo fala da formação de séries exaustivas das coisas. Essa primeira modalidade do esgotamento se manifesta de forma intrínseca no roteiro do espetáculo. Folheando as páginas do caderno de ensaio, notamos que se constituem listas de ações inspiradas pelas propostas dos atores. O roteiro final é uma lista, um quadro de 
ações retratando assim explicitamente as combinações exaustivas descritas por Deleuze:

A combinatória é a arte ou a ciência de esgotar o possível por disjunções inclusas. Mas o esgotado pode esgotar o possível, pois renunciou a toda necessidade, preferência, finalidade ou significação. Apenas o esgotado é bastante desinteressado, bastante escrupuloso. Ele é forçado a substituir os projetos por tabelas e programas sem sentido. (idem: 71)

Ora, o roteiro d'A Última Palavra É a Penúltima 2.o se revela, de fato, como um «programa sem sentido». Não que a obra não produza sentido, mas o seu sequenciar desnorteia constantemente, sem deixar ao espectador a possibilidade de se agarrar ao desenrolar de uma dramaturgia que tenha a narrativa como finalidade. Ao invés, o público assiste a um espetáculo cuja estrutura é tipicamente serial, pois traz um desfile de fatos e coisas de mesma natureza, mas nunca idênticas: passagens de silhuetas paulistanas que se apresentam sucessivamente, sem interrupção e sem lógica causal entre elas. São como «simples brincadeiras do tempo com o espaço, ora com uns brinquedos, ora com os outros» (ibidem), diria Deleuze citando Watt, de Beckett.

No caderno de ensaios, podemos identificar facilmente como essas «brincadeiras» foram pouco a pouco pautadas em inúmeras sequências de tópicos cuja ordem sofre diárias variações ao longo dos meses de ensaio. Nota-se que cada tópico corresponde a uma travessia que se define pela associação entre uma ação, uma figura e um objeto: «homem esfregando o vidro», «mulher comendo macarrão chinês em pote», «pessoas carregando cartazes publicitários»... Ora, essas passagens, que podem ser vistas como os átomos que constituem a dramaturgia do espetáculo, nascem de dinâmicas de improvisação exaustivas solicitadas pelos encenadores. Toda a composição d'A Última Palavra É a Penúltima 2.o se baseia em um jogo de combinações de ações e de objetos. Basta folhear o caderno de ensaios para percebermos como as listas compostas de séries de ações e objetos se sucedem ao longo da escrita do projeto. Um dos workshops fundador desta relação entre corpo e objeto aparece nas primeiras páginas do caderno de ensaio. É solicitado aos atores que recolham pela cidade objetos, segundo eles significativamente urbanos, e façam com estes propostas de passagens. 
Sair pela cidade. Achar um objeto que seja significativo para você. Pensar no percurso como objeto «prótese», objeto acoplado ao corpo/objeto que dê uma função para o objeto no corpo» - indicação para «workshop». (Monteiro, 2014)

Reconhece-se, na indicação da diretora acima, um aspecto tipicamente beckettiano: o caráter híbrido dos corpos-objetos. De fato, a obra do autor é povoada por «corpos-próteses»; citemos a mulher-monte dos Belos Dias, os velhos-lixeiras de Fim de Partida ou ainda os rostos-vasos de Comédia. O corpo não produz o acontecimento, ele é o acontecimento. Desta relação íntima entre os corpos e objetos, vão surgindo as figuras que performam pelo túnel, extenuando as potencialidades deste espaço.

Essa segunda modalidade de esgotamento dos possíveis surge já com o próprio dispositivo da encenação e se acentua durante o processo. No início dos ensaios, os diretores propuseram aos atores um exercício inspirado pela peça Quad, de Beckett, à qual Deleuze atribui certa parte de suas reflexões. Quad é pensado como um dispositivo quadrilateral para quatro atores que realizam um partitura de movimentos explorando ritmicamente todas as linhas da figura traçada, «a ordem, o curso e o conjunto tornam o movimento tão mais inexorável quanto ele é sem objeto, como uma esteira rolante que fizesse aparecer e desaparecer os móveis» (Deleuze, 2010: 88).

Partindo deste princípio de um circuito fechado onde os atores se definem por suas trajetórias, os encenadores propõem ao grupo duas horas de improvisações balizadas por pontos de passagem obrigatórios. Deste exercício, começam a surgir as séries exaustivas de passagens. Além disso, a exploração exaustiva do espaço da passagem, reforçada pelo uso das câmeras, extenua as possibilidades de ocupação do espaço, criando, como diria Deleuze relativamente à Quad, um «balé», «onde há substituição de toda história ou narração por um "gestus" como lógica das posturas e posições» (idem: 90).

Ora este «balé» urbano imaginado pelo Vertigem também se constrói através do estancar dos fluxos das palavras. Como já dissemos, A Última Palavra É a Penúltima 2.0 busca desfocalizar a atenção do espectador das vozes e das palavras e privilegiando o fluxo dos corpos. O esgotamento oral não é sinônimo de silêncio, muito pelo contrário, ele permite a emergência de outros corpos sonoros, como explica Deleuze ainda a respeito da poética beckettiana: «não se trata absolutamente de fazer silêncio, é preciso ver também o tipo de silêncio que se faz... [...] a última palavra é a penúltima» (idem: 73). 
A partir da citação que se tornou o título do espetáculo, foi proposto um workshop, no qual os atores deviam responder à provocação: «Qual palavra seria a sua penúltima?» $\mathrm{O}$ exercício ajudou a estabelecer a relação com a palavra dentro da dramaturgia. A ideia de que não haja ponto final ou fechamento da estrutura semântica das frases manifesta-se pela presença cíclica e repetitiva dos grupos de palavras, criando uma linguagem muitas vezes incompreensível. As vozes são cobertas por outros sons ou se expressam em línguas desconhecidas, criando um tratamento cacofônico da palavra. Pode considerar-se que o fluxo da palavra é estancado porque o valor semântico desta é interrompido pelos diferentes fatores da performance. O que importa não é a sintaxe das frases, nem o sentido das palavras, mas o jorro que as expulsa, o impulso oral dos corpos.

A relativização do valor semântico da fala, consequentemente, atribui às imagens um caráter ainda mais transitório. Sem se focalizar no corpo do ator, já que este não tende a expressar um significado pela fala, o espectador se deixa levar pela fugacidade das ações em fluxo. Assim se estabelece a última das modalidades do esgotamento definidas por Deleuze: «dissipar a potência da imagem» (2010, 84). Observando a construção das imagens beckettianas, Deleuze desenvolve a ideia de que:

O que conta na imagem não é o conteúdo pobre, mas a prodigiosa energia captada, prestes a explodir, fazendo com que as imagens nunca durem muito tempo. Elas se confundem com a detonação, a combustão, a dissipação de sua energia captada. (idem: 84-85)

As repetitivas e variadas travessias d'A Última Palavra É a Penúltima 2.o, impedindo a estagnação do fluxo urbano e imposição de uma situação de representação mimética, criam imagens de alta intensidade, «prestes a explodir» e efêmeras.

A este respeito, o ator Nicolas Gonzáles relata em sua entrevista um workshop que muito contribuiu para a apreensão deste modo de composição da imagem. Foi solicitado aos atores que andassem pela cidade durante uma hora olhando através de um pequeno espelho, como se vissem o fluxo urbano através dos reflexos de um retrovisor. Depois desta experiência, os atores voltavam para a passagem Xavier de Toledo e, alimentados pelas imagens, deviam propor travessias interruptas durante uma hora. A dinâmica criada por este workshop promove a dissipação 
da potência da imagem característica do fluxo contínuo das ações transeuntes. A visão retrovisora da cidade trazida pelo exercício dos espelhos ajudou os atores a experimentarem de forma física e concreta o que Deleuze diz quando formula que «a imagem é precisamente isso: não uma representação do objeto, mas um movimento no mundo do espírito» (2010: 85). A fugacidade das imagens d'A Última Palavra É a Penúltima 2.o produz um movimento contínuo do olhar do espectador. Este, mesmo sentado, se põe em movimento, no sentido em que o simples caminhar do seu olhar tomado pelo vaivém dos corpos produz em seu corpo a pulsação frenética da metrópole.

Fica claro, portanto, de que modo as quatro maneiras de esgotar o possível dinamizam e estruturam a dramaturgia d'A Última Palavra É a Penúltima 2.o. Resta ainda entender segundo que critérios os encenadores ordenaram a sequência de ações que constituem o roteiro do espetáculo. Para tanto, podemos nos referir a uma citação relembrada por Eliane Monteiro durante nossa entrevista:

A grande contribuição de Beckett à lógica é mostrar que o esgotamento (exaustividade) exige um centro de esgotamento fisiológico, mais ou menos como Nietzsche mostrava que o ideal científico exige uma forma de degenerescência vital. (idem: 71)

Partindo da ideia de esgotamento fisiológico, a encenadora volta-se para o fenômeno físico que se caracteriza justamente pela degenerescência progressiva das capacidades vitais do corpo, passando por três fases, que ela descreve:

A primeira fase é cerebral e traz enjoo, vertigem e angústia; a segunda caracteriza-se por convulsões generalizadas (contração dos músculos e relaxamento do esfíncteres); na terceira fase há lentidão respiratória levando ao sofrimento do miocárdio. (Monteiro, 2015)

O esgotamento fisiológico descrito foi determinante para a organização temporal das ações. Essas foram sequenciadas em função das características físicas das três fases do processo de asfixia. Vemos no caderno de ensaio como pouco a pouco as listagens iniciais se transformam nessas três fases, que formarão o roteiro final do espetáculo.

De fato, o roteiro final d'A Última Palavra É a Penúltima 2.o em nada parece com uma peça de teatro: não é dividido em cenas, não é construído 
por falas, não possui elenco de personagens, não conta nenhuma história e é praticamente ilegível por alguém que não tenha como decifrar as ferramentas de trabalho do grupo nele inscrito. Mas esse roteiro, riscado, sublinhado, amassado e anotado, como um eterno rascunho, carrega consigo todos os traços do esgotamento que caracterizam o processo criativo do qual emergiu, e talvez por isso seja a manifestação material mais clara do que poderíamos chamar de uma dramaturgia do esgotamento.

Determinando a escolha do lugar para a representação, a ausência de texto, a criação e ordem das ações, o esgotamento afeta toda a construção d'A Última Palavra É a Penúltima 2.o e revela-se portanto como principio ativo do espetáculo. Ativo e ao mesmo tempo invisível, já que nunca é tratado de maneira ilustrativa pelo grupo. Talvez seja este o aspecto mais impactante do trabalho: o esgotamento é palpável, sem, no entanto, se exibir de forma explicativa, pois de fato sua onipresença se manifesta na experiência fisiológica vivida pelo espectador durante a performance.

Seja por estar encurralado por vitrinas, seja por não entender aquilo que ouve, seja pela frenética atividade ocular exigida pelo fluxo das travessias, a composição d'A Última Palavra É a Penúltima 2.o cria um modo de percepção que se caracteriza pela exaustão do espectador. Ora, esta afetação fisiológica do espectador é, sem sombra de dúvida, o reflexo de uma dramaturgia remoída pelo esgotamento, esgotando até mesmo a atenção de seu espectador.

É por esta razão que se deve sublinhar que a ausência de uma estrutura textual pautada por falas não altera o teor político da proposta artística do Teatro da Vertigem. Pelo contrário, a radicalidade estética atingida pelo grupo neste trabalho revela, sim, uma importante carga política, pois, sem convocar explicações verbais, cria através da «fisicalidade» do próprio espectador a sensação do esgotamento urbano. Entrelaçando a escrita plástica e coreográfica com o fluxo natural da cidade, o espetáculo não se contenta em representar o esgotamento, mas transforma pelo esgotamento, graças à experiência física vivida pelo espectador, a maneira de olhar, ouvir e pensar a cidade. 


\section{REFERÊNCIAS BIBLIOGRÁFICAS}

ARAúJo, Antônio (2011), A Gênese da Vertigem, São Paulo, Perspectiva.

DELEUZE, Gilles (2010), Sobre o teatro: Um manifesto de menos-. O esgotado, trad. Ovídio de Abreu e Roberto Machado, Rio de Janeiro, Jorge Zahar Ed.

MON Te iro, Eliane (2014), caderno de ensaio d'A Última Palavra é a Penúltima 2.o escrito durante o processo criativo do espetáculo em setembro de 2014.

-- (2015), entrevista realizada no dia 13 de setembro.

\section{MARIA CLARA FERRER}

Maria Clara Ferrer é professora na Universidade Federal de São João del-Rei (Minas Gerais, Brasil), atuando nas áreas de direção teatral, cenografia e dramaturgia. Entre 2008 e 2015, lecionou na Université Sorbonne Nouvelle - Paris 3, onde também concluiu em 2014 sua tese de doutoramento, intitulada Devenir-paysage de La scène contemporaine: Le dépaysement du drame, sob a orientação de Joseph Danan. Em 2015, ministrou aulas na Université de Poitiers. Fortemente envolvida com a prática teatral, escreveu e dirigiu vários espetáculos, dentre eles Célébration, Le Grand Projet, La Fragilité. Em 2014, assistiu o diretor Antônio Araujo na criação do espetáculo Dire ce qu'on ne pense pas dans des langues qu'on ne parle pas, apresentado no Théâtre National de Bruxelles e no Festival de Avinhão. Como tradutora (português-francês), traduziu peças de Jean-Luc Lagarce, Copi, Rodrigo de Roure e Newton Moreno. 